\title{
Evaluation of Expressway Asphalt Pavement Performance Based on the Fuzzy Theory
}

\author{
Hongli Zhao ${ }^{1, \text { a }}$, Ruiran $\mathrm{Li}^{2, \mathrm{~b}}$, Yang Cui ${ }^{3, \mathrm{c}}$ and Guangyu Zhou ${ }^{4, \mathrm{~d}}$ \\ 1,2,3,4 Shandong water conservancy vocational college, Rizhao, China \\ a34617063@qq.com, b762679595@qq.com, c16312540@qq.com
}

\begin{abstract}
Keywords: degree of membership; asphalt pavement; pavement condition index; the fuzzy comprehensive evaluation.

Abstract: To more scientific evaluation of asphalt pavement performance, provide maintenance decision objective, accurate and comprehensive data, based on the fuzzy comprehensive evaluation method evaluation, this paper constructs the high grade highway asphalt pavement performance evaluation model. This paper is from four indicators of the pavement condition index, the structure strength index, driving quality index and lateral force coefficient to build the evaluation system, then establishes membership function and calculates the weight, then performance level is calculated by the maximum membership degree comprehensive evaluation method, finally through the actual case evaluation, the results show that the model can effectively solve the problem of high grade highway asphalt pavement performance evaluation.
\end{abstract}

\section{Asphalt Pavement Performance Evaluation}

Structural damage, the strength of structure, road surface roughness and surface sliding resistance is common asphalt pavement performance evaluation indicators ${ }^{[1]}$, pavement condition index $P C I$, the structure strength index $S S I$, driving quality index $R Q I$ and lateral force coefficient $S F C$ ( $B P N)$ constitutes the pavement performance evaluation system ${ }^{[2-3]}$, and the comprehensive evaluation index $P Q I$. At present, for the evaluation of comprehensive performance of asphalt pavement, the specification of highway asphalt pavement maintenance technology (JTJ 073.2-2001) and "highway technical condition evaluation criteria" (JTG H20-2007) are all adopted the method of weighted arithmetic mean to solve the $P Q I$. After many years of practice, the author found the method although calculation form simple, the result directly, can reflect the status of the road of technology state, however, the method can't be more really close to the objectively true state of road. So we introduce the fuzzy membership degree evaluation method, in order to make the evaluation results more objective, more realistic, more can reflect the general development level of the road.

1.1 Evaluation Index. For the calculation of the pavement performance index (coefficient), in order to facilitate comparative analysis, we can be summarized as shown in table 1 .

Table 1 Asphalt pavement performance index (coefficient) calculation formula

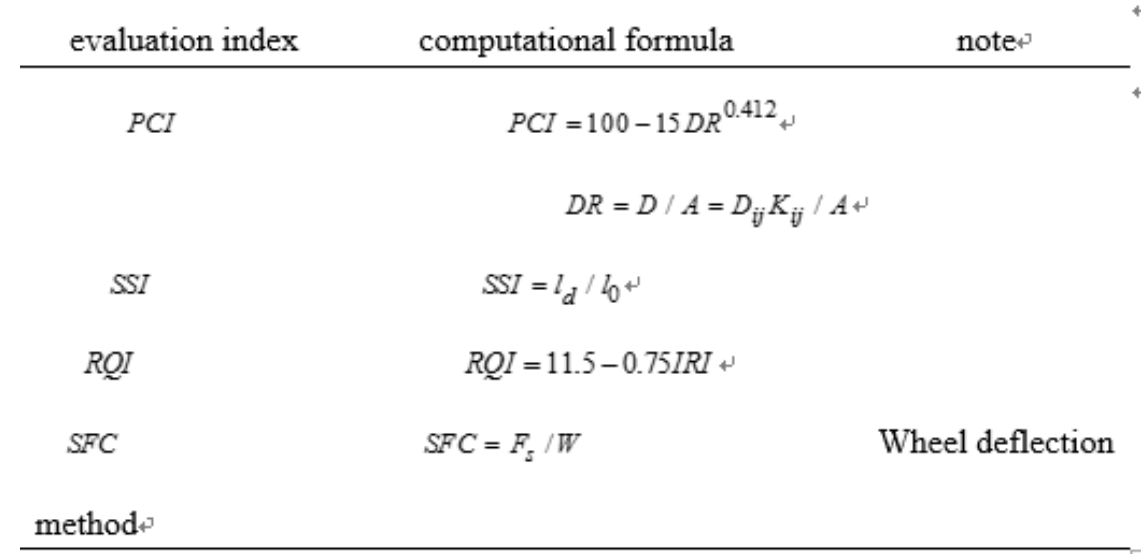

The indexes of asphalt pavement evaluation standard are shown in table $2^{[4]}$. 
Table 2 The index of asphalt pavement performance evaluation standard

\begin{tabular}{|c|c|c|c|c|c|}
\hline $\begin{array}{l}\text { rating } \\
\text { evaluation } \\
\text { index }\end{array}$ & $A$ & $B$ & $C$ & $D$ & $E$ \\
\hline$P C I$ & {$[85,+\infty)$} & {$[70,85)$} & {$[50,70)$} & {$[40,50)$} & $(-\infty, 40)$ \\
\hline SSI & {$[1.2,+\infty)$} & {$[1.0,1.2)$} & {$[0.8,1.0)$} & {$[0.6,0.8)$} & $(-\infty, 0.6)$ \\
\hline$R Q I$ & {$[8.5,+\infty)$} & {$[7.0,8.5)$} & {$[5.0,7.0)$} & {$[4.0,5.0)$} & $(-\infty, 4.0)$ \\
\hline$S F C$ & {$[0.5,+\infty)$} & {$[0.4,0.5)$} & {$[0.3,0.4)$} & {$[0.2,0.3)$} & $(-\infty, 0.2)$ \\
\hline
\end{tabular}

The formula for computing the index table 1 and table 2 index evaluation criterion, we can see that the formula to calculate the form is more dispersed, index evaluation standard is not unified: $P C I$ is 100 scale, but SSI, RQI and SFC is out, when we use the subentry index and comprehensive evaluation of asphalt pavement, technology of asphalt pavement of actual status discrimination is not accurate. So we want to get a more considerable evaluation results, the first unify the range of values of the sub-index, overcome the model itself defects, and make some improvement on model structure. 1.2 Model Refinement. Because $P C I$ is 100 scale, but $S S I, R Q I$ and $S F C$ is out, so, we first need to unify their domain and use the math unified domain nonlinear function to deal with. Setting up a nonlinear function of $S S I, R Q I$ and $S F C$ is as follows:

$$
y=\frac{100}{1+a e^{b x}}
$$

Among them: $y$-- stay range, range of $0 \sim 100$;

$x$-- corresponding function variables; $a, b$-- stay coefficient.

For formula (1), we can make use of the highway technical condition evaluation criteria and literature [5] obtaining the value of $\mathrm{a}$ and $\mathrm{b}$, then the corresponding function, the corresponding relational is as shown in table 3 and table 4.

Table 3 Corresponding relations between $P C I-D R$

\begin{tabular}{|c|c|c|c|c|}
\hline$P C I$ & 90 & 80 & 70 & 60 \\
\hline$D R$ & 0.4 & 2.0 & 5.5 & 11.0 \\
\hline
\end{tabular}

Table 4 Corresponding relations between $R Q I-I R I$

\begin{tabular}{|c|c|c|c|c|}
\hline$R Q I$ & 90 & 80 & 70 & 60 \\
\hline$I R I_{\text {high }}$ & 2.3 & 3.5 & 4.3 & 5.0 \\
\hline$I R I_{\text {low }}$ & 3.0 & 4.5 & 5.4 & 6.2 \\
\hline$P C I$ & 90 & 80 & 70 & 60 \\
\hline$D R$ & 0.4 & 2.0 & 5.5 & 11.0 \\
\hline
\end{tabular}

Table 5 Corresponding relations between $S S I /$ - SSI

\begin{tabular}{|c|c|c|c|c|}
\hline$S S I^{\prime}$ & 90 & 80 & 70 & 60 \\
\hline$S S I$ & {$[1.2,+\infty)$} & {$[1.0,1.2)$} & {$[0.8,1.0)$} & {$[0.6,0.8)$} \\
\hline
\end{tabular}


Table 3, table 4 and table 5 are given the corresponding value of the ends, according to providing corresponding relation, using the formula (1), we can obtain the values of $R Q I^{\prime}, S S I^{\prime}$ and $S F C^{\prime}$, the calculation results are shown in table 6.

Table 6 Formula to calculation about $R Q I^{\prime}, S S I^{\prime}$ and $S F C^{\prime}$

\begin{tabular}{|c|c|}
\hline $\begin{array}{l}\text { evaluation } \\
\text { index }\end{array}$ & modified index calculation \\
\hline$R Q I$ & $R Q I^{\prime}=\frac{100}{1+0.0387 e^{0.459 I R I}}$ \\
\hline SSI & $S S I^{\prime}=\frac{100}{1+35.42 e^{-6.80 S S I}}$ \\
\hline$S F C$ & $S F C^{\prime}=\frac{100}{1+20.91 e^{-10.965 S F C}}$ \\
\hline
\end{tabular}

After unification domain, asphalt pavement performance evaluation standard is shown in table 7.

Table 7 Asphalt pavement performance evaluation standard

\begin{tabular}{|r|ccccc|}
\hline evaluation index & $A$ & \multicolumn{2}{c}{$B$} & $C$ & $D$ \\
\hline PCI $^{\prime}$ RQI $^{\prime} S S I^{\prime} S F C^{\prime}$ & 92 & 80 & 65 & 50 & 30 \\
\hline
\end{tabular}

\section{Fuzzy Membership Function Model}

Membership function for a wider application of fuzzy mathematics in engineering provides the basis of theory practice widely, and has a prominent position in the fuzzy mathematics. It is a branch of fuzzy evaluation function, and it is affected by many factors make a kind of very effective multi-factor comprehensive evaluation decision method, its characteristic is the evaluation results more objectively ${ }^{[6]}$.We apply it to evaluate comprehensive performance, the asphalt surface can be more close to reality, and to provide a more scientific basis for our future decision making and maintenance. The basic definition as follows:

A fuzzy set is a pair ( $\mathrm{U}, \mathrm{A})$, where $\mathrm{U}$ is a set and $A: U \rightarrow 0,1$ a membership function. For each $x \in U$, the value $A x$ is called the grade of membership of $x$ in $U, A$. For $x \in U$, if $A x=0$, the $x$ is called not included in the fuzzy set $U, A$; if $A x=1$, the $x$ is called fuzzy included in $U, A ; x$ is called a fuzzy member if $0<A \quad x<1$.

2.1 Construct Membership Function. According to the classification principles of the highway technical condition evaluation criteria, the performance of asphalt pavement conditions can be divided into excellent, good, medium, poor, five-grades. For the convenience of using function, we can use $A, B, C, D$ and $E$ instead of five-grades. According to the category of the asphalt pavement performance assessment rank, we can construct a membership function corresponding to the 5-grades by using the principle of the membership grade ${ }^{[7]}$.

Setting $U_{A}=[0,92], x \in[0,92]$, 


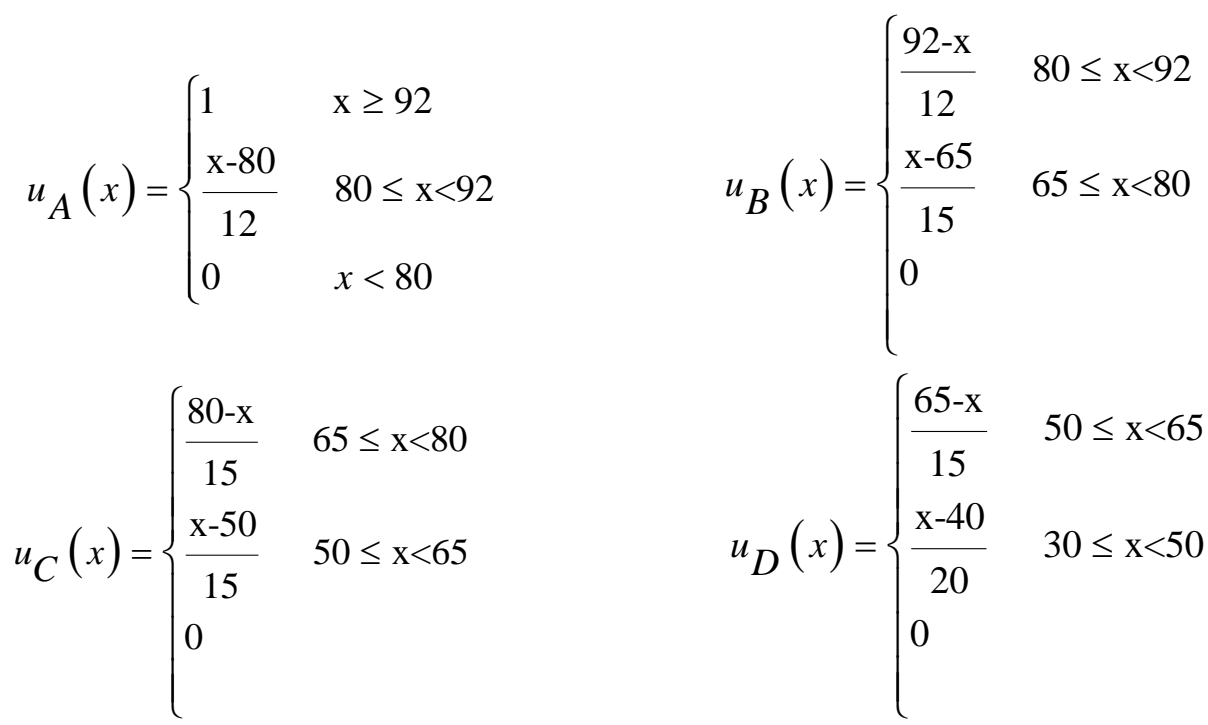

$$
\begin{aligned}
& u_{E}(x)= \begin{cases}1 & \mathrm{x}<30 \\
\frac{50-\mathrm{x}}{20} & 30 \leq \mathrm{x}<50 \\
0 & \end{cases}
\end{aligned}
$$

According to the above function formula, we can get four performance indicators of membership functions.

2.2 Construct the Fuzzy Relationship Matrix. According to the category of the evaluation results of each index, the distribution is obtained by using the corresponding membership function. That is $U_{i}=\left(r_{i 1}, r_{i 2} \ldots r_{i j}\right)$, where $r_{i j}$ is the $j-t h$ fuzzy set's grade of the $i-t h$ index. Then we can construct a matrix about the grade of the membership.

2.3 Structural Weight Coefficient Matrix. The factors weight vector can be represented as:

$$
A=\left(a_{1}, a_{2}, \ldots, a_{n}\right)
$$

Among them: $a_{1}+a_{2}+\ldots+a_{n}=1$

$a_{i}$--- The factors weight value.

\subsection{Evaluation of the Results}

By the fuzzy algorithm for the fuzzy relation matrix and weight coefficient matrix, we can get the membership grade matrix of the comprehensive index with respect to each evaluation degree.

$$
B=A \circ R=a_{1}, a_{2}, \ldots a_{j}\left[\begin{array}{cccc}
r_{11} & r_{12} & \cdots & r_{1 j} \\
r_{21} & r_{22} & \cdots & r_{2 j} \\
\vdots & \vdots & \vdots & \vdots \\
r_{j 1} & r_{j 2} & \cdots & r_{j j}
\end{array}\right]=c_{1}, c_{2}, \ldots, c_{j}
$$

Among them: $\quad r_{i j}$--- As the indicators of the membership degree of fuzzy subsets.

According to the principle of maximum membership degree, $c=\max \left\{c_{j}\right\}$ is the optimal results.

\section{Engineering Application}

Shandong province highway asphalt pavement, through measurement and conversion of three groups of $P C I^{\prime}, R Q I^{\prime}, S S I^{\prime}$ and $S F C^{\prime}$, respectively, and the value is shown in table 8 . 
Table 8 Values of $P C I^{\prime}, R Q I^{\prime}, S S I^{\prime}$ and $S F C^{\prime}$

\begin{tabular}{|c|c|c|c|c|}
\hline \multirow{2}{*}{ stake mark } & \multicolumn{4}{|c|}{ conversion indicators } \\
\cline { 2 - 5 } & $P C I^{\prime}$ & $S S I^{\prime}$ & $R Q I^{\prime}$ & $S F C^{\prime}$ \\
\hline$K 1+500$ & 86.2 & 78.4 & 74.5 & 84.6 \\
\hline$K 11+500$ & 78.8 & 84.6 & 82.2 & 85.8 \\
\hline$K 21+500$ & 84.6 & 76.8 & 84.4 & 76.8 \\
\hline
\end{tabular}

The comprehensive evaluation of the results is shown in table 9 (Taking an example of $K 1+500$ ).

Table 9 Comprehensive evaluation of the results

\begin{tabular}{|c|c|c|c|c|c|c|}
\hline evaluatio & \multirow{2}{*}{$\begin{array}{c}\text { weight } \\
\mathrm{n} \text { index }\end{array}$} & \multicolumn{5}{|c|}{ meefficien } \\
\cline { 3 - 7 } & $A$ & $B$ & $C$ & $D$ & $E$ \\
\hline$P C I^{\prime}$ & 0.25 & 0.5167 & 0.4833 & 0.0000 & 0.0000 & 0.0000 \\
\hline$S S I^{\prime}$ & 0.35 & 0.0000 & 0.8933 & 0.1067 & 0.0000 & 0.0000 \\
\hline$R Q I^{\prime}$ & 0.10 & 0.0000 & 0.6333 & 0.3667 & 0.0000 & 0.0000 \\
\hline$S F C^{\prime}$ & 0.30 & 0.3833 & 0.6167 & 0.0000 & 0.0000 & 0.0000 \\
\hline$\sum_{i=1}^{n} a_{i} \times r_{i j}$ & 1.00 & 0.2442 & 0.6185 & 0.0740 & 0.0000 & 0.0000 \\
\hline
\end{tabular}

note: Weight coefficient is determined according to the specification of highway asphalt pavement maintenance technology and combining the importance to determine evaluation index.

According to the above results, the formula (4) available:

$$
\begin{aligned}
& C_{K 1+500}=A \bullet B=\left(c_{1}, c_{2}, c_{3}, \ldots c_{j}\right)=(0.2442,0.6185,0.0740,0.0000,0.0000) ; \\
& C_{K 11+500}=A \bullet B=\left(c_{1}, c_{2}, c_{3}, \ldots c_{j}\right)=(0.2975,0.6825,0.0200,0.0000,0.0000) ; \\
& C_{K 21+500}=A \bullet B=\left(c_{1}, c_{2}, c_{3}, \ldots c_{j}\right)=(0.1325,0.7289,0.1386,0.0000,0.0000) .
\end{aligned}
$$

According to the maximum membership degree principle, the above three sections of maximum membership degree of the corresponding level of asphalt pavement are all good.

\section{Summary}

When evaluating performance of asphalt pavement, this paper not only improved the calculation model of the indexes, but also introduced the introduction of fuzzy membership degree as an evaluation method of asphalt pavement performance, this largely reflects the objectivity of pavement performance, at the same time for the asphalt surface maintenance decision making and maintenance provides more scientific basis. The application of engineering examples, further verified the fuzzy membership degree evaluation method scientific.

\section{References}

[1] Yao Zukang. Pavement management system [M]. Beijing: people's traffic press, (1993).

[2] Song Jinhua, Song Xiulian, etc. The study of the comprehensive evaluation system of the asphalt pavement [J]. Journal of hebei university of technology, (2004), p.16-18

[3] Zhang Dongqing, Jia Shuang. High grade highway asphalt pavement performance evaluation method [J]. Journal of chang 'an university, (2005), (2) :11-15 
[4] The ministry of communications highway research institute. JTJ073.2-2001, highway asphalt pavement maintenance specification [S]. Beijing: people's traffic press, (2001).

[5] Zi Jianmin. Pavement management system and management [M]. Guangzhou: south China university of technology press, (2002).

[6] Xie Jijian Liu Chengping. Fuzzy mathematics and its application [M]. Wuhan: huazhong university of science and technology press,(2006).

[7] Liu Tangzhi, wan donghua, etc. Based on fuzzy membership degree of asphalt pavement using performance comprehensive evaluation [J]. Journal of wuhan university of technology, (2013), 5 (1) : 58-61 